$\xi=-$ 国

\title{
Heat Treatment Technology of Porous Building Materials with Predictability of Thermophysical Properties
}

\author{
Mustafa Baba Babanli ${ }^{1}$, Liubov Shumska ${ }^{2}$, Maryna Leshchenko $^{3^{*}}$ \\ ${ }^{1}$ Azerbaijan State Oil And Industry University, Azerbaijan \\ ${ }^{2}$ Poltava Oil And Gas College Of Poltava National Technical Yuri Kondratyuk University, Ukraine \\ ${ }^{3}$ Poltava National Technical Yuri Kondratyuk University, Ukraine \\ *Corresponding Author E-Mail: Mv.Leshchenko@Gmail.Com
}

\begin{abstract}
The work is devoted to theoretical and experimental research of thermophysical features of the creation of new porous heat insulating materials, precisely: research of thermodynamic parameters of the heating processes, swelling and drying of materials; substantiation of the choice of the raw mixture method formation and determination of the optimal energy parameters of the swelling process; development of mathematical models of material heat treatment process and methods of basic technological parameters determination; development of advanced technologies for thermal protection of buildings and power equipment. Experimentally determined dependencies of technological parameters of heat treatment of the raw material mixture in the discharge, its composition, which allows obtaining material with minimal thermal conductivity. Also, the resulting dependencies ensure to find the required mode of heat treatment for the given thermophysical properties. The experimental setup has been developed, which provided to determine the basic laws of heat transfer of porous material, on the basis of which data were obtained, which allow to carry out an estimation of heat transfer and exchange characteristics of the new dispersed porous material necessary for technological calculations. A complex mathematical model of the heat energy mode of the building was created, as well as a program for solving the equations of this model, which makes it possible to determine the basic energy characteristics.
\end{abstract}

Keywords: constructions envelope, energy efficiency, mathematical modeling, passive house, porous insulation, thermal conductivity, thermal processes.

\section{Introduction}

The demands for increasing the thermal protection of buildings and structures, the main consumers of energy, are an important subject of state regulation in most countries of the world. These requirements are also considered from the point of environmental protection view, rational use of non-renewable natural resources and reduction of the greenhouse effect, as well as other harmful substances on the atmosphere. The application of effective insulation for passive homes is an actual issue.

These norms refer to part of the general task of energy saving in construction. Simultaneously with the establishment of effective thermal protection of buildings, measures are taken to increase the efficiency of buildings engineering equipment, reduce energy losses during its development and transportation, as well as to reduce the consumption of thermal and electric energy.

The solution of this problem can be accomplished by theoretical and experimental substantiation of the optimal temperature-time modes, which provide the lightest heat insulating material at its maximum strength. The decision of this topical problem is possible by forming a defective cellular structure in the process of mechanical and thermal treatment of the raw mixture based on clay. At the same time, more effective use of its potentialities was considered on the basis of in-depth understanding of the porous structure formation mechanism. However, with the improvement of the thermal and technical properties of the enclosing structures, the characteristics of the bearing elements deteriorate. In particular, the porosity of the cement-sand component reduces the strength characteristics of the metal, and the introduction of finely dispersed additives reduces the durability of concrete.

The analysis of the known technological solutions has shown that the thermodynamic parameters of the porous structures production require clarification.

The analysis of publications has shown that in full are described various constructive scheme insulation, in particular, the thermophysical properties of new heat insulating materials [1-4] and methods of their production [5-7]. The questions of effective insulation of fencing structures were considered in works [8-10].

Thus, the work is devoted to the development and detailed scientific substantiation of the thermodynamic parameters of porous heat insulating materials production.

\section{Main Body}

Primarily, the analysis of scientific and technical works devoted to the technologies of the porous heat-insulating materials production for various applications as heat insulation in construction and power engineering was carried out.

The influence of structural characteristics of porous materials on the intensity of heat and mass transfer processes, the effect of porosity on the effective coefficient of thermal conductivity of the porous material, and the effect of moisture in the porous material on the heat transfer have been investigated.

It is shown that solving the problem of creating effective porous heat insulating materials and technologies of their production is inextricably linked with scientific research in the field of energy transfer in the porous structure at the stages of swelling, hardening 
and drying provided the lowest thermal conductivity and density are ensured. The specified properties of materials are determined by the magnitude of their porosity, the ratio of micro and macroporosity, the properties of interposing materials, forming a kind of bearing frame, which in turn is determined by the technology of production, the type of raw materials and the conditions for their preparation. All of the above stipulates special requirements for the formation of the structure of the material in order to ensure at the same time relatively high strength and durability.

The next step of this work was to determine the rational composition of the raw material mixture for thermal pore formation. The possibility of using clay as an additional lowtemperature gasifies for the processes of thermal flooding of the raw material mixture and the effect of aluminum as additive on thermal structure formation was investigated. Complex influence "clay $+\mathrm{Al}_{2} \mathrm{O}_{3}-$ swelling temperature" was estimated by the obtained values of heat conductivity of the finished material (Fig. 1).

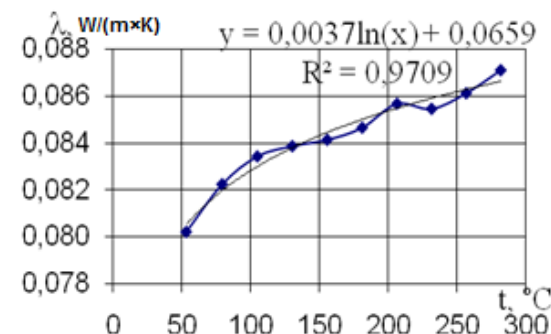

Fig. 1: The dependence of thermal conductivity on temperature swelling

The influence of the temperature of the pure clay swelling on the thermal conductivity is unambiguous, but the raw material mixture with the addition of clay after spraying forms a porous structure at lower temperatures, and the dependence of the thermal conductivity on the temperature of swelling is more complex (Fig. 2).

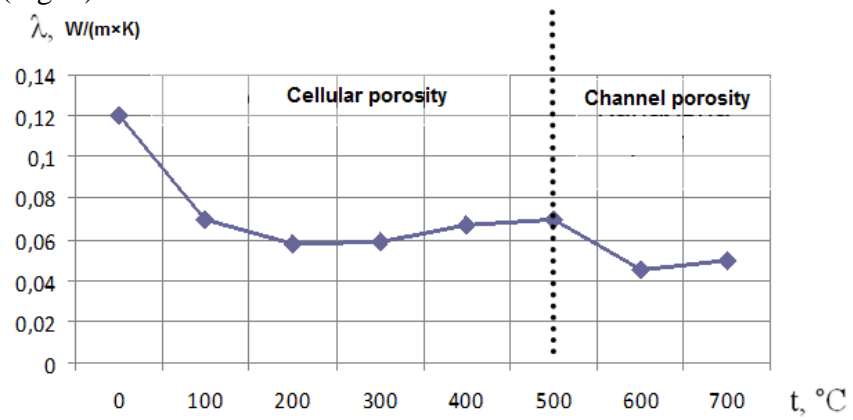

Fig. 2: The dependence of the raw mixture thermal conductivity with the addition of clay and $\mathrm{Al}_{2} \mathrm{O}_{3}$ on temperature

At the heat treatment of the raw material mixture in the temperature range $120-500 \mathrm{C}$ formed a sufficiently strong insulation material with low thermal conductivity. Increasing the temperature of swelling leads to a decrease in the coefficient of thermal conductivity of the finished material, but at the same time the strength of the material decreases. Temperature range 500$800^{\circ} \mathrm{C}$ gives the channel porosity.

For these processes, the constant of the pore formation rate was determined.

In fig. 3 and 4 shows the dependence of the moisture content of the examined samples on the duration of heat treatment at different temperatures and the rate of evaporation (pore formation). At zero humidity the air-dry state is adopted. From these dependencies it is evident that the variation curve for moisture in samples at pore formation is consistent with the standard curve of humidity change during drying. In this case, the first portion of the curve (the area of constant humidity) is not expressed due to its insignificance, which is explained by high temperatures.

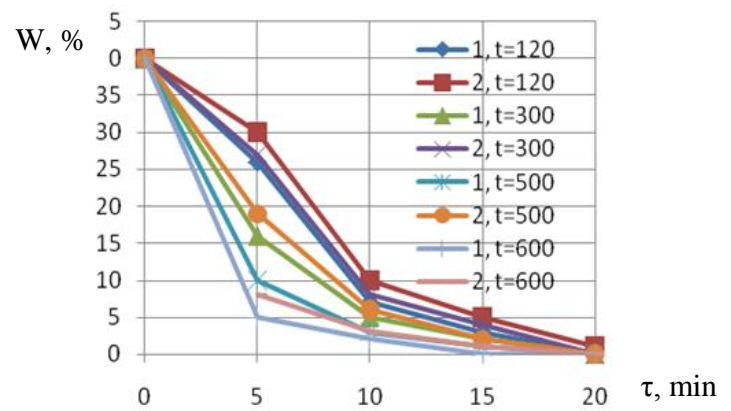

Fig. 3: The change of humidity during heat treatment $\mathrm{dW} / \mathrm{d} \tau$

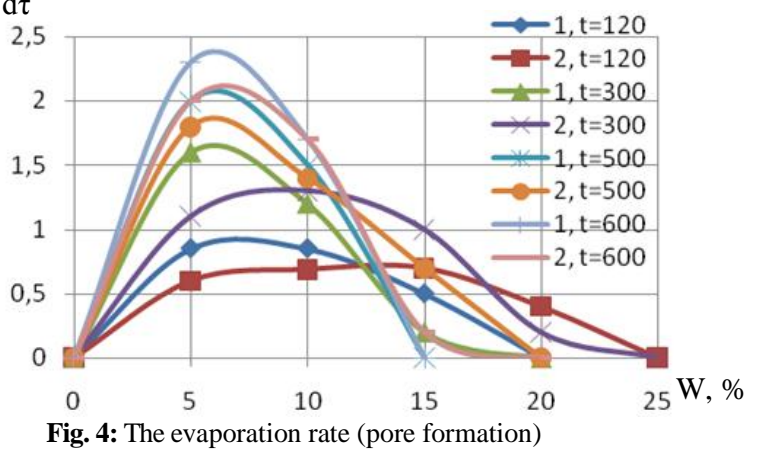

The conducted experiments allow determining the basic regularities of the porosity change in the materials during their heat treatment.

Curves of the rate change of moisture in the swelling material are similar to the drying curves and also have three periods (the period of increasing, constant and decreasing moisture removal rate). It is possible to determine three periods of pores formation. The first period is the stage of reducing the number of pores which depends on the material. In more plastic is held a slight decrease in the number of pores and in less plastic place a significant reduction in the number of pores. The second stage is an equable decreasing the quantity of pores in the material. With increasing temperature, the decrease in the number of pores occurs more intensively, due to a more intense increase in pore volume. The third stage is the overgrown pores. Consequently, the addition of clay to the raw material mixture not only increases the amount of gasifies, but also changes the rheology of the raw material mixture so that the porosity of the material reaches the maximum values.

The next stage of the work was the research of the technological parameters of structuring to confirm of the material, where in the first stage, studied the features of phase formation, which occurs when the hydration of the raw composition in combination with the additives mentioned in the previous step.

For implementation practical research, chamotte or pure building clay was added to the raw material. The objective of the study was to determine the optimal ratio of additives masses in terms of energy consumption to the implementation of the thermal fluctuation process, strength of the material, porosity and thermal conductivity. It is obvious that thermal conductivity and energy consumption should be minimal. Phase's transformation, their kinetics and intensity were investigated using a differentialthermal analysis of the raw material mixture (DTA) (Fig. 5, Fig. 6). At results of the experiment, the horizontal axis was graded at temperature. By the position of the peak of the endothermic process, the temperature interval of phase transitions was investigated.

Changes, which took place during the heating, showed three endothermic effects: $146^{\circ}, 500^{\circ}$, and $720^{\circ}$ (average temperature intervals in Fig. 1-4). A large endothermic effect due to the removal of absorbed water is observed at $146^{\circ} \mathrm{C}$, and the step observed on the curve at $300^{\circ} \mathrm{C}$ indicates removal of interpacket water. The second effect $\left(450-550^{\circ} \mathrm{C}\right)$ corresponds to the removal of the constitutional water (bound into the form of $\mathrm{OH}$ ). The endothermic effect at $720^{\circ} \mathrm{C}$ explains the removal of $\mathrm{OH}$-ions. 


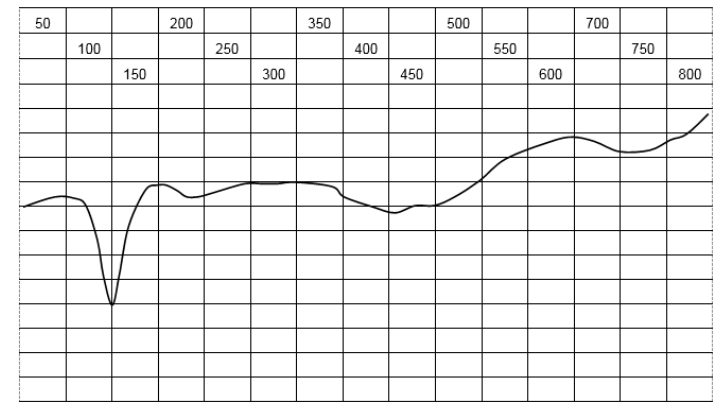

Fig. 5: DTA of raw material mixture with a content of 75 mass fractions of clay

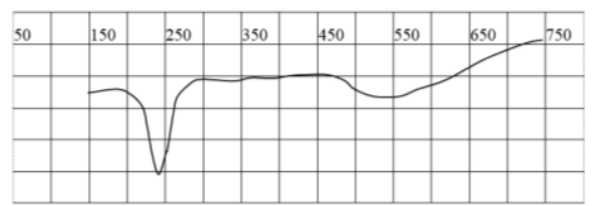

Fig. 6: DTA of raw material mixture with a contentof 25 mass fractions of clay

As it can be seen from the data chart, the optimum temperature range for dehydration of the mixture is within $146-720^{\circ} \mathrm{C}$.

The raw material mixture was swollen at the indicated temperature intervals and investigated the thermophysical properties of the obtained materials. The method of differential-thermal analysis using the theory of the planned experiment was used to analyze the influence of the raw mixture composition and the thermal modes of swelling on the properties of the obtained materials.

The morphology and porosity of the samples were determined by optical methods. According to this method, the macroscopic parameters of porosity inside metric interval with a lower bound of $10 \mathrm{~m} \mu$ and upper bound of $5 \mathrm{~mm}$ are determined. The specified interval characterizes the strength parameters of the substance and parameters of heat and mass transfer.

For the first endothermic minimum, the material was pulled out with small, almost spherical pores. Most of them were of minimal size. Swelling of the raw material mixture in the second endothermic minimum gives a mixed porosity (spherical cellular and channel). The material becomes less durable. When the third endothermic minimum is lowered, channel porosity is formed predominantly. Such material has the least strength, but also the smallest thermal conductivity.

Thermal conductivity in porous building materials is due to various interacting physical processes can be reduced to three types: conduction, convection and radiation. The contribution of these processes to the total heat conductivity of building materials has been repeatedly analyzed. Convection in air layers with a thickness of less than $5 \mathrm{~mm}$ is practically absent to a temperature difference of $100^{\circ} \mathrm{C}$. As shown above, expanded materials have pores of considerably smaller sizes. The pore size and porosity cannot be determinative indicators in terms of the formalization of the recording of the main functional dependencies, since at the same porosity the materials may have different porous forms, and, accordingly, different heat conductivity and, not less important, strength. Therefore, for further considerations, we will use as aggregation indicator of density. The material density was measured by mass and volume for raw materials mixed with characteristic temperatures (three endothermic minima).

The thermal conductivity of the materials was measured using the IT $\lambda$-400 device.

Figures 7 and 8 show graphs of the dependence of heat conductivity on density.

The dispersion of the values of the thermal conductivity at small and average values of $\gamma$ is relatively small in relation to the large values of $\gamma$, this can be explained by the fact that the low density of the material determines the thermal conductivity of air in pores, and with a high material density, the thermal conductivity of its skeleton, which can vary greatly depending on the mineralogical composition.

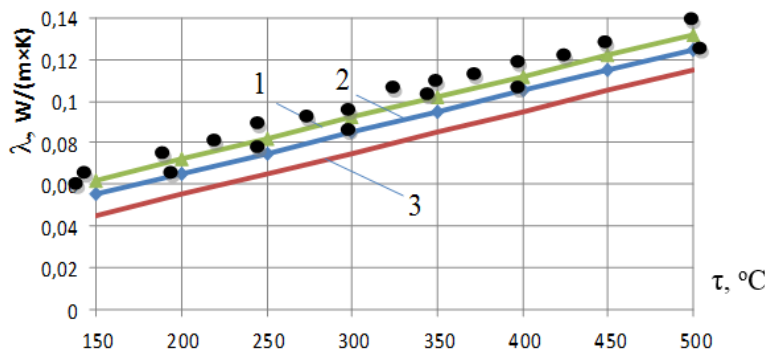

Fig. 7: The dependence of thermal conductivity coefficient on the materials density: 1) perlite; 2) sample (75 mass fractions of clay), swollen at a temperature of $\left.700^{\circ} \mathrm{C} ; 3\right)$ sample (160 mass fractions of clay), swollen at a temperature of $700^{\circ} \mathrm{C}$

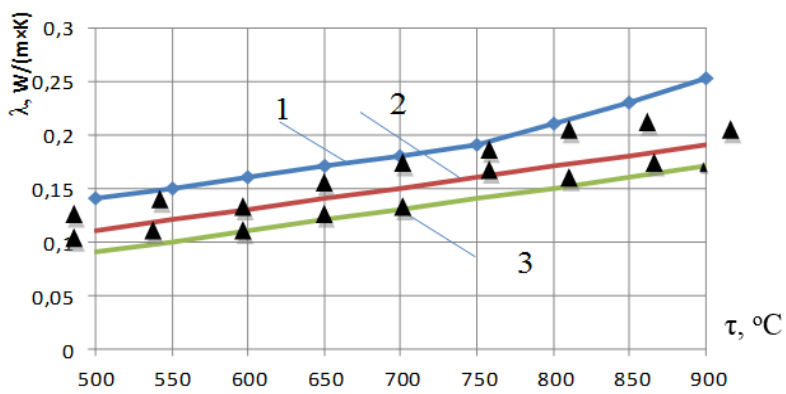

Fig. 8: The dependence of thermal conductivity coefficient on the materials density: 1) claydite; 2) sample (75 mass fractions of clay), swollen at temperatures of $160-300^{\circ} \mathrm{C}$; 3) sample (160 mass fractions of clay), swollen at temperatures of $160-300^{\circ} \mathrm{C}$

Building materials used for thermal insulation of fencing structures are porous and the influence of water that is in pores can be substantial, as the thermal conductivity of water is 25 times greater than the thermal conductivity of air. But water can be differently distributed in the porous space of the material and at the same time have a different effect on its thermal conductivity at one and the same humidity. Water can be evenly distributed over the surface of the material or completely fill pores, forming thermal bridges, heat transfer can also be carried out by diffusion and subsequent condensation of water vapor on the walls of pores. The isotherms of sorption-desorption of water vapor are extremely important characteristics that determine the accuracy of calculations of the moisture regime of structures.

For the study of the regularities of sorption moisture materials used desiccators method. The obtained data are shown in Figure 9.

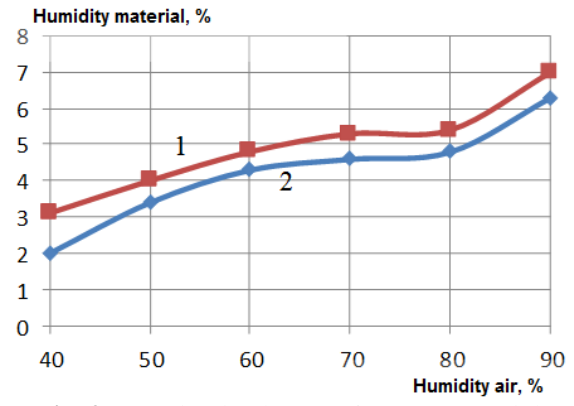

Fig. 9: Sorption isotherms of porous material:

1) sample №1, swelling under conditions of the third endothermic minimum; 2) sample №2, swelling at a temperature of $140^{\circ} \mathrm{C}$

Open channel porosity leads to more moisture of the material (Graph 1). Water absorption of porous ceramic products depends, above all, on the presence of open porosity of the material. The studies were conducted on samples with a density that corresponds to endothermic minima in DTA graphs, 200,500 and $700 \mathrm{~kg} / \mathrm{m}^{3}$. Study of the water absorption kinetics of porous ceramic products in comparison with the equilibrium cellular claydite-concrete showed that with a decrease in the average density of porousceramic products, their water absorption increases (Fig. 10), which 
is typical of most light porous materials, and is explained primarily by an increase in porosity of the material.

Water absorption, \%

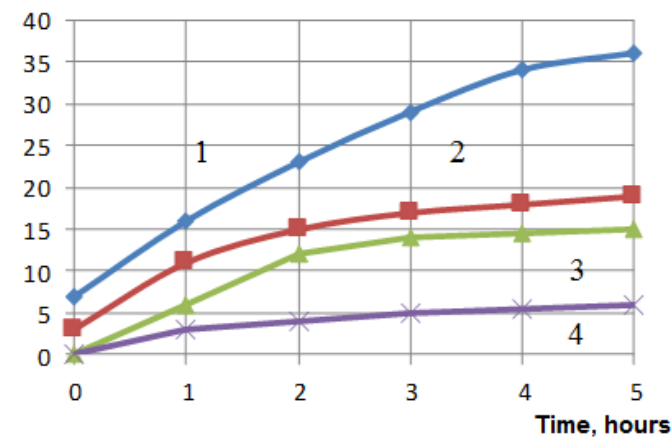

Fig. 10: The water absorption of porous materials: 1) cellular concrete, 500 $\mathrm{kg} / \mathrm{m}^{3}$; 2) claydite-concrete, $500 \mathrm{~kg} / \mathrm{m}^{3}$; 3) sample, $500 \mathrm{~kg} / \mathrm{m}^{3}$, swelling under conditions of the second endothermic minimum; 4) sample, swelling at a temperature of $140^{\circ} \mathrm{C}$

Comparing the indicators of water absorption of porous ceramic products with traditional wall materials, it can be noted that for porosity ceramic products, these indicators are approximately 4-6 times lower than, for example, in equilibrium ceramist concrete and cellular concrete, primarily due to the presence of small closed pores.

The researches of the basic physical-mechanical, hydrophysical and heat-engineering properties of structural and thermal insulation porous-ceramic products testify to the increased thermal protection characteristics and strength characteristics of the material, which are somewhat superior to the properties of traditional materials for enclosing structures, for example, claydite-concrete, foam concrete.

Characteristics of the strength of materials were determined by standard techniques. Material, screwed at $160^{\circ} \mathrm{C}$, in 1.6 times prevails for the strength of expanded clay (Fig. 11).

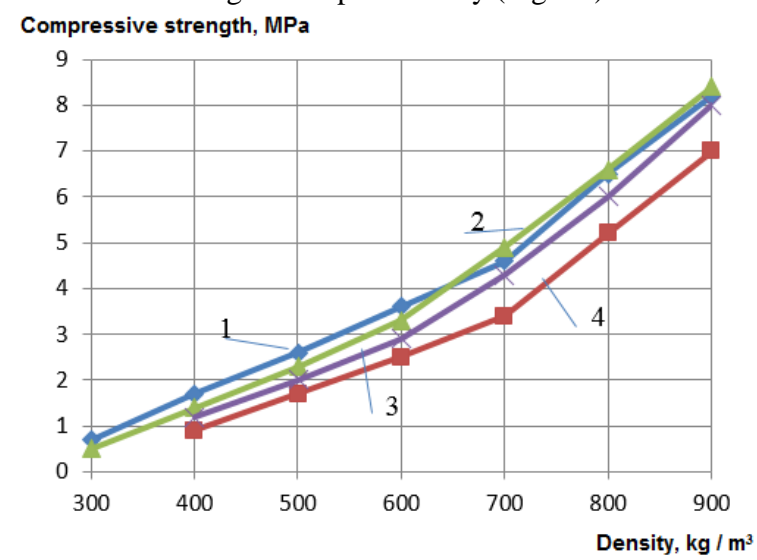

Fig. 11: The dependence of the strength of porous materials on the density compared with the equilibrium claydite-concrete - 4 and foam concrete - 1 ; 3- sample, swelling under the conditions of the third endothermic minimum; 2 - sample, swelling at a temperature of $140^{\circ} \mathrm{C}$

The basic physico-mechanical, hydrophysical and heatengineering properties of obtained materials are summarized in Table 1 .

The given data testify that new porous heat insulating materials exceed the traditional ones by a number of indicators.

As shown above, all the main properties of materials are directly interconnected. Moreover, if the material is produced with allowance for the minimum thermal conductivity, we obtain a structure with a minimum compressive strength. Such material should be used as thermal insulating filler. Plates for heatinsulating structures must be produced at moderate temperatures (within the limits of the first endothermic minimum). Then we get solid material, but its thermal conductivity will be higher. It is easy to find correlations based on the received data.
It remains to find out what content of the components of the raw material mixture will be the most rational in terms of the value of the endeavor, which we can fix with DTA-graphs.

Table 1: Basic properties of swelling materials

\begin{tabular}{|c|c|c|c|c|c|}
\hline \multirow{2}{*}{ Material } & $\begin{array}{c}\text { Density, } \\
\mathrm{kg} / \mathrm{m}^{3}\end{array}$ & $\begin{array}{c}\text { Average } \\
\text { strength, } \\
\mathrm{MPa}\end{array}$ & $\begin{array}{c}\text { Coefficient of } \\
\text { thermal } \\
\text { conductivity, } \\
\mathrm{W} /(\mathrm{m} \mathrm{K})\end{array}$ & $\begin{array}{c}\text { Sorption } \\
\text { humidity, } \\
\text { at air } \\
\text { humidity } \\
90 \%\end{array}$ & $\begin{array}{c}\text { Water } \\
\text { absorption, } \%\end{array}$ \\
\hline \multirow{2}{*}{ Claydite } & 300 & 0,2 & 0,13 & 9,7 & 21 \\
\cline { 2 - 6 } & 900 & 4 & 0,25 & 8,1 & 11 \\
\hline $\begin{array}{c}\text { Foam } \\
\text { concrete }\end{array}$ & 300 & 0,8 & 0,14 & 9,5 & 24 \\
\hline \multirow{2}{*}{ Sample } & 300 & 8,2 & 0,29 & 8 & 15 \\
\cline { 2 - 6 } & 900 & 8,4 & 0,09 & 10 & 15 \\
\hline
\end{tabular}

Such studies are performed on the above methods using the theory of experiment planning. Factors for controlling the intensity of the process of flood are the following: the content of clay (mass), alkali metal hydroxide, water and flowing temperature.

Control parameters: $Y_{1}$ is thermal conductivity of the expanded material; $\mathrm{Y}_{2}$ is the strength of the material. Data processing was performed according to the standard algorithm of the experiment planning method.

Dependence of the influence of factors and their interactions on the measured parameters, as well as the adequacy of the models received, were evaluated for errors $s_{x}^{2}$ for the $Y_{i}$. indicators. After data processing, the equations for calculating the thermal conductivity and strength are calculated taking into account the influence of the determinants that changed in accordance with the plan of the matrix of the experiment in a given range of values:

$$
\begin{aligned}
& Y_{1}=0,038-0,055 X_{2}-0,1 X_{3}-0,01 X_{4}+0,06 X_{1}^{2}+ \\
& +0,062 X_{2}^{2}+0,032 X_{3}^{2}+0,05 X_{4}^{2}
\end{aligned}
$$

$$
\begin{aligned}
& Y_{2}=25,6-3,8 X_{2}-6 X_{3}-3 X_{4}+4 X_{1}^{2}+ \\
& +4,3 X_{2}^{2}+3,5 X_{4}^{2}-3 X_{3} X_{4}
\end{aligned}
$$

The adequacy of the models obtained was checked by Fisher's criterion.

The obtained results show that with an increase in the concentration of clay and water, the temperature of heat treatment, we obtain a material with a minimum coefficient of thermal conductivity.

When heat treated within the temperatures corresponding to the third endothermic effect, materials from $\lambda \approx 0,07 \mathrm{~W} /(\mathrm{m} \mathrm{K})$, but in this case the porosity was channel due to the intensity of vaporization.

The obtained equations allow determining the investigated parameters by calculation, depending on the given factors of the pore formation technology. Solving the equation together, we obtain the optimal combination of the calculated parameters.

The next stage of the study was to propose a method for evaluating the parameters of heat treatment of the material, which allows determining the main technological parameters of this process.

Heat treatment of moist materials is a technological process that is accompanied by structural and mechanical changes in the dry matter. The main task of the technology of thermal swelling of the raw material mixture is the creation of combined heat treatment methods taking into account the basic stages of the physicochemical transformation of the raw mixture (dehydration, gas formation, crystallization of the framework, drying), which would ensure not only the intensification of the process, but also the best technological properties of the dried materials.

The optimal mode of heat treatment of this material is determined by more thorough and deep research on the transfer of heat and moisture inside the material. Knowledge of the basic laws of heat 
and mass transfer in relation to the drying process, the peculiarities of different drying methods allowed approaching the choice of a rational way of heat treatment on a scientific basis.

The problem of heat treatment of moist materials involves the transfer of heat and mass inside the body (internal problem) and in the boundary layer at the interface between the phases (external problem). The amount of moisture removed depends on the degree of development of these processes. When heated, the moisture content on the surface decreases, and this creates a concentration drop across the body. Therefore, in the body there is a flow of moisture from the deep layers to the surface, towards which the flow of heat is directed. Thus, when heating moist materials, there are complex processes of moisture and heat exchange, which mutually influence the enthalpy and moisture content of both the heated material and the environment.

The process of heating is a non-stationary process of moisture and heat transfer, for which the system of differential equations of transfer in the absence of a gradient of total pressure $(\nabla P=0)$ has the following meaning:

$$
\begin{gathered}
C \rho_{O} \frac{\partial t}{\partial \tau}=\frac{\partial}{\partial x}\left(\lambda \frac{\partial t}{\partial x}\right)+\varepsilon \cdot r \cdot \rho_{O} \frac{\partial U}{\partial \tau}, \\
\frac{\partial U}{\partial \tau}=\frac{\partial}{\partial x}\left(a_{m} \frac{\partial U}{\partial x}+a_{m} \cdot \delta \frac{\partial t}{\partial x}\right),
\end{gathered}
$$

where $t(x, \tau)$ - temperature function, $\mathrm{x}$ - coordinate, $\tau$ - time; $U(x, \tau)$ - function of moisture content, $\lambda, C, \rho$ - coefficient of thermal conductivity, specific heat capacity and material density; $\rho_{O}$ - the density of absolutely dry material; $a_{m}$ and $\delta$ coefficients of diffusion and thermal diffusion of moisture, $\varepsilon-$ evaporation criterion; $r$ - the heat of steam generation. Boundary conditions in general:

$$
\begin{aligned}
& -\lambda\left(\frac{\partial t}{\partial x}\right)_{n}+q_{n}(\tau)-r(1-\varepsilon) j_{n}(\tau)=0, \\
& a_{m} \rho_{o}\left(\frac{\partial U}{\partial x}\right)_{n}+a_{m} \cdot \delta \cdot \rho_{O}\left(\frac{\partial t}{\partial x}\right)_{n}+j_{n}(\tau)=0,
\end{aligned}
$$

where $q_{n}(\tau)$ - heat transfer intensity;

$j_{n}(\tau)$ - the intensity of water exchange.

Initial conditions are as follows:

$U=f(x) ; \quad t=f(x)$.

The solution of the system of equations (3)-(7) can be obtained using a computer.

Figure 12 shows the experimental drying curve and the temperature diagram of the wet material $(\mathrm{R}=0,01 \mathrm{~m})$ in the heating process in a drying cabinet at a constant temperature of the heating air $t_{C}=160^{\circ} \mathrm{C}$ (temperature of the wet thermometer $t_{\mathcal{M}}=44^{\circ} \mathrm{C}$ ). According to the scheme for the consistent removal of moisture from the material marked singular points (1-5), corresponding to a specific species of connection of moisture with the body. Accordingly, the heating process can be divided into five stages: - the first stage (0-1) passes with the constant moisture content and ends when the temperature of the wet thermometer is reached on the surface of the material $\left(t_{n}=t_{\mathcal{M}}\right)$;
- the second stage (1-2) removes capillary moisture contained in macropores, whose binding energy is insignificant; at the end of the stage, the temperature in the center is equal to the temperature of the wet thermometer $\left(t_{u}=t_{\mathcal{M}}\right)$, and the drying rate increases to the maximum;

- the third stage (2-3) the material the duct moist macropores are removed; the average volume moisture content is reduced to the end of the stage to the value of the maximum hygroscopic $\bar{U}_{\mathcal{M . 2}}$, corresponding to the first critical point of $K_{l}$, on the drying curve; the drying rate practically does not change;

- the fourth stage (3-4) is to remove of the capillary moisture of the micropore; the medium volume moisture content of the material is reduced to the maximum adsorption $\bar{U}_{\text {M.a }}$ corresponding to the second critical point of $K_{2}$ on the drying curve; the drying rate falls;

- the fifth (4-5) stage removes the most firmly bound moisture of the multimolecular and monomolecular adsorption, respectively; the average moisture content of the material varies from $\bar{U}_{\text {M.a }}$ to equilibrium $\bar{U} p$.

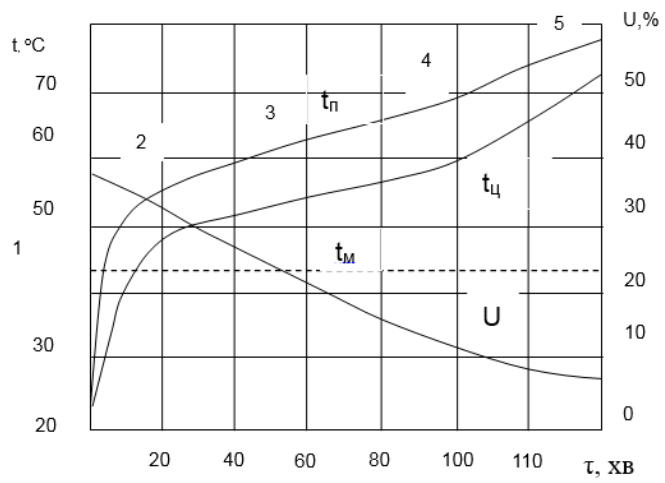

Fig. 12: Surface temperature $t_{n}(\tau)$, center $t_{u}(\tau)$ and medium volume moisture content $\bar{U}(\tau)$ of the plate during heating at constant temperature of the heating medium $t_{t_{C}}=160^{\circ} \mathrm{C}$.

To determine the temperature field of the material in the first stage, when moisture evaporation does not occur, known solutions are used, from which the initial conditions for the next stage are determined. The process of heating on the second, third and subsequent stages occur with the deepening of the surface of the evaporation of the corresponding type of moisture from the outer surface inside the material. As a result of evaporation of moisture inside the material creates an increased pressure of the steam/air mixture (pores). Experimental data showed that the distribution of temperature at the thickness of the material at the end of each stage is parabolic. Therefore, using the formulas for the regular heating regime, it was possible to determine the effective coefficients of heat transfer, which in total take into account the transfer of heat and moisture.

After the experimental research was carried out, the thermal protection of buildings was simulated when heated with new material. Physical and mathematical models of thermal processes of the building are created.

The external environment affects the thermal parameters of the microclimate through the enclosing structures (there are processes such as heat and moisture transmission, infiltration and exfiltration) and internal energy connections between the premises. Therefore, the thermal protection of the building is a passive factor in the formation of the thermal microclimate. Therefore, one of the most urgent requirements of the present-day is the increase of energy efficiency of buildings, which is being realized, first of all, due to the strengthening of their thermal protection.

The equation of heat balance air environment of premises for such a building is given by: 


$$
\begin{aligned}
& { }^{-c}{ }_{B} m_{B} \frac{d t}{d z}= \\
& =\sum q_{3 H}^{K} F_{3 H}^{K}+\sum q_{B H}^{K} F_{B H}^{K}+q_{C . O .}^{K}{ }^{F}{ }_{C . O .}^{K}{ }^{ \pm} \\
& \pm \sum_{l=1}^{n} q_{M . K .}^{K}{ }^{K}{ }_{M . K .}^{K}+Q_{I H \Phi}+Q_{\Pi Б}^{K}
\end{aligned}
$$

where $c_{B}$ - air thermal capacitance; $m_{B}$ - indoor air mass heating facilities; $\mathrm{q}^{\mathrm{K}}{ }_{3 \mathrm{H}}, \mathrm{q}^{\mathrm{K}}{ }_{\mathrm{BH}}, \mathrm{q}_{\text {о.П. }}^{\mathrm{K}} \mathrm{q}_{\text {M.К. }}^{\mathrm{K}}$ - convective heat flows in accordance with external and internal construction building envelop heat capacity, boiler and low thermal construction building envelop heat capacity; $\mathrm{F}^{\mathrm{K}}{ }_{3 \mathrm{H}}, \mathrm{F}^{\mathrm{K}}{ }_{\text {BH }}, \mathrm{F}^{\mathrm{K}}{ }_{\text {O.П. }}, \mathrm{F}^{\mathrm{K}}{ }_{\text {M.K. }}$ - the area of heat transfer surfaces according to convective heat flow thermal capacity external and internal building constructions envelop, boiler and low thermal heat capacity building constructions envelop; $\mathrm{Q}_{\mathrm{IH} \Phi}$ - infiltration heat; $\mathrm{Q}^{\mathrm{K}}{ }_{\text {Пь }}-$ convective household (technological) heat.

$c_{B} m_{B}=\sum c_{i} m_{i}$

where $c_{i}$ - air thermal building aerial environment capacitance; $m_{i}$ -building aerial environment mass elements.

The equation of radial heat flow building aerial environment heat balance is given by:

$$
\begin{aligned}
& \sum q_{3 H}^{\Pi} F_{3 H}^{\Pi}+\sum q_{B H}^{\Pi} F_{B H}^{\Pi}+ \\
& +q_{C . O .{ }^{F} . O .}^{\Pi} \pm \sum q_{M . K .}^{\Pi}{ }_{M . K .}^{\Pi}+Q_{\Pi Б}^{\Pi}=0
\end{aligned}
$$

where $\mathrm{q}^{\Pi}{ }_{\text {зн }}, \mathrm{q}_{\text {ВН }}^{\Pi}, \mathrm{q}_{\text {о.П. }}^{\Pi} \mathrm{q}_{\text {м.К. }}^{\Pi}$ radial heat flows in accordance to heat capacity external and internal building construction envelope, boiler and low heat capacity building constructions envelope; $\mathrm{F}_{3 \mathrm{H}}^{\Pi}, \mathrm{F}_{\text {BН }}^{\Pi}, \mathrm{F}_{\text {о.П. }}^{\Pi} \mathrm{F}_{\text {м.к. }}^{\Pi}$ the area of heat transfer surfaces respectively radial heat flow heat capacity external and internal building construction envelope, boiler and low heat capacity building construction envelope; $Q^{\Pi}$ пь - household beam (technology) heat.

To assess the quantitative effect of the building insulation transient thermal processes mathematical model was created.

The main considered elements are external and internal building construction envelope, building heating system and interior room climate.

When setting this task simplifying terms were used: real heating system is replaced by an equivalent emissivity heating unit; multilayer external building structures envelope with perfect thermal contact between the layers were considered; temperature field in their one-dimensional; specific heat capacity at constant operating temperature range; low thermal building constructions envelope heat accumulating capacity (windows, doors) is zero; uneven distribution of temperature in the room is neglected.

In steady state conditions can be set as the initial temperature. As disturbing action coolant temperature graph in «quality» program regulations will be used.

The automatic controller mode software adjustment is described by equation where there are several indeterminate. Automatic control allows adjusting the temperature of the coolant in the heating system depending on outside temperature and internal air of the building. The estimated coolant temperature in the heating system is described by the equation:

$\tau_{10}=t_{B}+\left(t_{O . \Pi .}^{C P}-{ }^{C}{ }_{B}\right) \cdot Q^{0,8}+\left(\tau_{1}-t_{O . \Pi .}^{C P}\right) \cdot Q$,

where ${ }_{B}$ - building internal air temperature $\left(\right.$ ex. $\left.18^{\circ} \mathrm{C}\right)$;

${ }^{t} \mathrm{CP} . \Pi$. - the average temperature of the boiler $\left(\right.$ ex. $\left.82.5^{\circ} \mathrm{C}\right)$; $\tau_{1}$ - coolant temperature in the heating supply pipelines, serving as a heating schedule (ex. dimensions $95 / 70^{\circ} \mathrm{S}$ ); $Q-$ the relative amount of heat required for heating, depending on the outside temperature and is given by:

$$
Q=\frac{{ }^{t} B-t_{3}}{{ }_{B}+t_{3 P}},
$$

where $t_{3}$ - current extraneous air around the building.

The required temperature of the coolant in the heating system is described by the equation:

$$
\tau_{10}^{\text {НЕОБХІД }}=t_{10}+K_{t} \cdot 0,1 \cdot\left(t_{B}^{\text {НЕОБХІД }}-t_{B}^{\text {ФКТИЧ }}\right),
$$

where $K_{t}$-factor impact indoor air temperature of the building, which is taken within 1-99.

The work of the regulator valve is described by the equation:

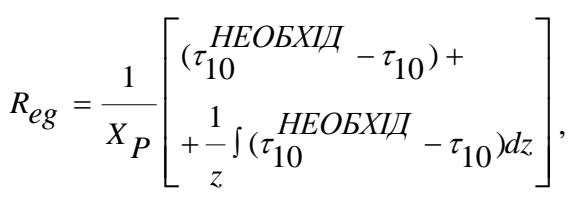

where $X_{P}-$ proportional zone regulator (for the regulator adopted within 1-250);

$\tau_{10}$ - coolant temperature in the heating system, ${ }^{\circ} \mathrm{C}$.

The automatic controller proportional-integral-type regulation mode software is described by the equation:

$$
\tau_{10}^{\text {НЕОБХІД }}=t_{10}+K_{t} \cdot 0,1 \cdot\left(t_{B}^{\text {НЕОБХІД }}-t_{B}^{\text {ФКТИЧ }}\right)
$$

The system heat balance equation of the equivalent tube boiler heating system is given by:

$$
\left\{\begin{array}{l}
\tau_{2(\infty)}={ }^{t} C T+\left(\tau_{1}-t_{C T}\right) e^{-\frac{a_{1} F_{1}}{c G}} \\
c_{1} m_{1} \frac{d \tau_{2(z)}}{d z}=\left(c_{1} G+a_{1} F_{1}\right)\left(\tau_{2(\infty)}-\tau_{2(z)}\right) \\
c_{1} m_{1} \frac{d \tau_{C P(z)}}{d z}=c_{1} G\left(\tau_{1}-\tau_{2(z)}\right)-a_{1} F_{1}\left(\tau_{C P(z)}{ }^{-t} C T(z)\right) \\
{ }^{c} C T^{m} C T \frac{{ }^{m} C T(z)}{d z}=a_{1} F_{1}\left(\tau_{C P(z)}{ }^{-t} C T(z)\right)- \\
\left.-\left[a_{2}^{K} F_{2}^{K}\left({ }^{K} C T(z)-t_{B}\right)+a_{2}^{\Pi} F_{2}{ }^{\Pi}{ }^{(t} C T(z)-{ }_{R}\right)\right]
\end{array}\right.
$$

where $c_{1}, m_{1}$ - thermal capacitance and the weight of coolant heating systems; $\mathrm{z}$ - time; $\mathrm{G}$ - coolant flow in thermal quarterly network (elevator); $\tau_{1}-$ coolant temperature in the heat supply pipelines quarterly network; $\tau_{C P}-$ the average temperature of the coolant in the heating system; $a_{1}$ - coefficient of heat transfer on the inner wall of the coolant equivalent; $\alpha_{2}{ }^{\Pi}, \alpha_{2}{ }^{\mathrm{K}}-$ according to coefficient of radiation and convective heat transfer on the outside wall of the coolant equivalent; $F_{1}$ - the area of the inner surface of the appliance; $\mathrm{F}_{2}{ }^{\Pi}, \mathrm{F}_{2}{ }^{\mathrm{K}}$ - respectively the external surface area of the coolant convection and radiation component; 
$\mathrm{c}_{\mathrm{CT}}, \mathrm{m}_{\mathrm{CT}}, \mathrm{t}_{\mathrm{CT}}$-respectively specific heat, weight and temperature of the coolant wall equivalent; $t_{B}-$ temperature internal air space; $t_{R}$ - the average radiation temperature of indoor air space.

The system of equations (16) consists of the following equations: - the first equation in the system of equations allows to find the temperature of the coolant in the return pipeline, which will be installed in the heating system after the completion of the transient processes. This equation is derived from a system of equations written for any mean temperature value under stationary thermal conditions:

$$
\left\{\begin{array}{c}
{ }_{\tau_{C P}-t_{C T}}=\frac{\tau_{1}-\tau_{2}}{\ln \frac{\tau_{1}-t_{C T}}{\tau_{2}-t_{C T}}} \\
a_{1} F_{1}\left(\tau_{C P}-t_{C T}\right)=c_{1} G\left(\tau_{1}-\tau_{2}\right)
\end{array},\right.
$$

- the second equation in the system of equations (16) allows to find the temperature of the coolant in the return pipe as a function of time, the spending of the coolant in the heating system and the heat loss in the environment;

- the third equation allows to find the average temperature of the coolant in the heating system $\tau_{C P(z)}$ at any given time;

- the fourth equation in the system of equations allows to find the temperature of the wall equivalent to the heat transfer of the heating device $t_{\mathrm{ST}}$.

The thermal equilibrium of the internal air of the building has the form:

$$
\begin{aligned}
& c_{B} m_{B} \frac{d t}{d z}= \\
& =a_{2}{ }^{K} F_{2}\left({ }^{t} C T(z){ }^{-t} B(z)\right)-a_{2}{ }^{\Pi} F_{2}\left({ }^{t} C T(z){ }^{-t} R(z)\right)- \\
& \left.{ }^{-a_{B} F_{3 K}\left({ }^{(t} B(z)\right.}{ }^{-t} H K(0, z)\right)-a_{B} F_{B K} \times\left({ }_{B(z)}{ }^{-t} B K(\delta / 2, z)\right)-\text {, } \\
& { }^{-c} \Pi^{G}{ }_{I H \Phi}\left(t_{B(z)}{ }^{-t}{ }_{H(z)}\right)-\sum a_{B}{ }^{K} F_{M K}{ }^{\left(t_{B(z)}\right.}{ }^{-t} M K(z){ }^{-} \\
& \left.-\sum a_{B}{ }^{\Pi} F_{M K}{ }^{(t} R(z){ }^{-t} M K(z)\right)
\end{aligned}
$$

where $c_{B}-$ air thermal capacitance; $m_{B}$ - weight indoor air heating premises; $a_{B}$ - heat transfer coefficient on the inner surfaces of construction envelope; $\mathrm{F}_{3 \mathrm{~K}}, \mathrm{~F}_{\mathrm{BK}}, \mathrm{F}_{\mathrm{MK}}$ - area under external and internal protections and low thermal constructions envelope; $t_{3 K(0, z)}, t_{B K(6 / 2, z)}, t_{M K(z)}-$ temperature according to the internal surfaces of external, internal and low thermal constructions envelope; $G_{\mathrm{IH} \Phi}$ - infiltration air flow.

The next element of thermal and humidity processes mathematical model is a system of differential equations describing the transient thermal conditions thermal capacity constructions envelope which would bring the temperature on the surface and in the outer section of the multilayer thermal capacity constructions envelope. This system consists of a differential Fourier heat equation for each of the layer construction envelope:

$$
\frac{\partial t_{3 K(X, Z)}}{\partial z}=\frac{\lambda_{i}}{c_{i} \rho_{i}} \cdot \frac{\partial t_{3 K(X, Z)}^{2}}{\partial x^{2}},
$$

with boundary conditions at the outer surface $(x=\delta)$ : $-\lambda_{3 K} \frac{\partial t_{3 K}}{\partial x}(\delta, z)=\alpha_{3}^{K+\Pi}\left(t_{3 K(\delta, Z)}-t_{3(Z)}\right)$,

and at the inner surface $(x=0)$

$$
\begin{aligned}
& -\lambda_{3 K} \frac{\partial t_{3 K}}{\partial x}(0, z)=\alpha_{B}^{K}\left(t_{B(Z)}-t_{3 K(0, Z)}\right)+ \\
& +\alpha_{B}^{\Pi}\left(t_{R(Z)}-t_{3 K(0, Z)}\right)
\end{aligned}
$$

Between the layers of design apply boundary conditions of the fourth kind.

$\lambda_{1} \frac{\partial t_{1}}{\partial x_{1}}(\delta, z)=\lambda_{2} \frac{\partial t_{2}}{\partial x_{2}}(0, z)$

where $t_{3 K(X, Z)}-$ the temperature inside the outer wall, which depends on the coordinates $\mathrm{x}$ and time $\mathrm{z},{ }^{\circ} \mathrm{C} ; \lambda_{i}-$ thermal conductivity and the layer construction envelope $\mathrm{W} / \mathrm{m} \cdot{ }^{\circ} \mathrm{C} ; \lambda_{3 K}-$ external wall thermal conductivity, $\mathrm{W} / \mathrm{m} \cdot{ }^{\circ} \mathrm{C} ; \delta_{i}-$ the thickness of the layer of the outer wall; $\alpha_{3}{ }^{K+\Pi}-$ heat transfer coefficient on the outside construction envelope, $\mathrm{W} / \mathrm{m} \cdot{ }^{\circ} \mathrm{C} ; \alpha_{B}{ }^{\kappa}, \alpha_{B}{ }^{\Pi}-$ ratios under convective and radiant heat at the inner surface of the enclosure, $\mathrm{W} / \mathrm{m}^{2} \cdot{ }^{\circ} \mathrm{C}$. each layer: Initial data are set stationary temperature distribution in

$t\left(x_{i}, \infty\right)=t(0, \infty)-x_{i}\left(t(0, \infty)-t\left(\delta_{i}, \infty\right)\right) / \delta_{i}$,

where $\delta_{i}-$ the thickness of the first layer; $x_{i}-$ spatial coordinate; $t$ - heat- layer.

The temperature on the surface of internal walling (walls, floors, interfloor constructions) can be found by solving the system of equations of thermal balance of these structures.

Thermal processes in heat capacity internal envelope are described by the equations, which consists of a differential heat equation:

$\frac{\partial t_{B K(X, Z)}}{\partial z}=\frac{\lambda_{i}}{c_{i} \rho_{i}} \cdot \frac{\partial t_{B K(X, Z)}^{2}}{\partial x^{2}}$,

while boundary conditions at the center of the wall:

$-\lambda_{B K} \frac{\partial t_{B K}}{\partial x}(0, z)=0$

and on its outer surface:

$-\lambda_{B K} \frac{\partial t}{\partial K}\left(\delta_{i}, z\right)=$

$=\alpha_{B}^{K}\left(t_{B K\left(\delta_{i}, Z\right)}-t_{B(Z)}\right)+\alpha_{B}^{\Pi}\left(t_{B K\left(\delta_{i}, Z\right)}-t_{R(Z)}\right)$,

and boundary conditions of the 4th kind of on the verge of materials:

$\lambda_{i} \frac{\partial t_{i}}{\partial x_{i}}(\delta, z)=\lambda_{i+1} \frac{\partial t_{i+1}}{\partial x_{i+1}}(0, z)$ 
The temperature on the inner surface of the outer low heat capacity constructions envelope can be found using the equality of heat flows in internal and external surfaces of these structures:

$$
\left\{\begin{array}{l}
q_{M K}=\alpha_{3}\left(t_{M K(\delta)}-t_{H}\right) \\
q_{M K}=\frac{\lambda_{M K}}{\delta_{M K}}\left(t_{M K(0)}-t_{M K(\delta)}\right) \\
q_{M K}=\alpha_{B}^{K}\left(t_{B}-t_{M K(0)}\right)+\alpha_{B}^{\Pi}\left(t_{R}-t_{M K(0)}\right)
\end{array},\right.
$$

Where $q_{M K}-$ heat flow through low heat capacity exterior constructions envelope; $t_{M K(\delta)}, t_{M K(0)}-$ temperature on the outside and on the inside surface of the construction envelope. The basis of determining the humidity of construction materials is the differential equation of diffusion of water vapor sorption medium:

$$
\xi_{i} \rho_{i} \frac{\partial e}{\partial z}=\frac{\partial}{\partial x}\left(\mu_{i} \frac{\partial e}{\partial x}\right),
$$

where $\xi_{i}$ - and relative vapor capacity-layer material g/kg; density, and the layer of material, $\mathrm{kg} / \mathrm{m}^{3} ; e-$ partial pressure, $\mathrm{Pa} ; z-$ time of the water vapor movement, $c ; \mu_{i}-$ vapor permeability coefficient, and the layer of material, $\mathrm{g} /(\mathrm{m} \cdot \mathrm{s} \cdot \mathrm{Pa})$; $x$ - spatial coordinate, $\mathrm{m}$.

To calculate the moisture processes buildings equation (21) should be supplemented with boundary conditions of the 3rd kind. These boundary conditions at the internal and external surfaces of the outer wall can be given by:

$$
\begin{gathered}
\mu_{1} \frac{\partial e_{1, z}}{\partial x}=\beta_{B}\left(e_{B}-e_{1, z}\right) \\
\mu_{n} \frac{\partial e_{n, z}}{\partial x}=-\beta_{3}\left(e_{n, z}-e_{3}\right)
\end{gathered}
$$

where $\mu_{1}, \mu_{n}-$ vapor ratio in accordance with the internal and external layer construction, $\mathrm{g} /(\mathrm{m} \cdot \mathrm{s} \cdot \mathrm{Pa}) ; \beta_{B}, \beta_{3}-$ moisture ratio at the internal and external surfaces $\mathrm{g} /\left(\mathrm{m}^{2} \cdot \mathrm{s} \cdot \mathrm{Pa}\right) ; e_{B}, e_{3}-$ the partial pressure of water vapor in the air according to the inner and outer side walls, $\mathrm{Pa} ; e_{1}, e_{n}-$ the partial pressure of water vapor according to the internal and external surfaces of structures, $\mathrm{Pa}$. The relative vapor capacity material can be determined by a formula $\mathrm{g} / \mathrm{kg}$

$$
\xi_{i}=1000 \frac{d \omega_{i}}{d \phi_{i}},
$$

where $\omega_{i}-$ humidity and mass-layer material $\% ; \varphi_{i}-$ relative humidity, $\%$.

Coefficient of moisture $\beta_{B}$ depends on temperature, humidity, air mobility at the surface. In terms of natural convection can be calculated by the formula, $\mathrm{g} /\left(\mathrm{m}^{2} \cdot \mathrm{s} \cdot \mathrm{Pa}\right)$

$$
\beta_{B}=1,192 \cdot 10^{-8} \Delta t^{\frac{1}{3}} \Delta e^{\frac{2}{5}},
$$

where $\Delta t-$ the temperature difference between air and surface constructions envelope; $\Delta e-$ partial pressure difference in the air and on the surface of the wall, $\mathrm{Pa}$.

$$
\begin{aligned}
& \Delta e=e_{B}-e_{1, z}, \\
& \Delta t=t_{B}-t_{1, z} .
\end{aligned}
$$

In the conditions of the turbulent air mode, characteristic of the external surface of the enclosing structure, the coefficient of water exchange depends mainly on the speed of this air, $w_{\Pi}(\mathrm{m} / \mathrm{s})$.

The partial pressure of saturated water vapor in Pa contained in air at temperatures range $-30 \div+20{ }^{\circ} \mathrm{C}$, can be approximate by the dependence:

$$
E=479+(11,52+1,62 t)^{2}
$$

The data obtained was verified experimentally. The purpose of experimental research was to test the developed mathematical models for determining the thermal state of the enclosing structure of the building from the new material, as well as to assess the degree of their accuracy.

The simulation of the heat-humidity mode of the enclosing structure at the programmed heat release was carried out at the experimental stand, which is based on the regulation of the heat release in the room. The scheme of the installation as a whole and its general view are presented in Figure 13.

a)

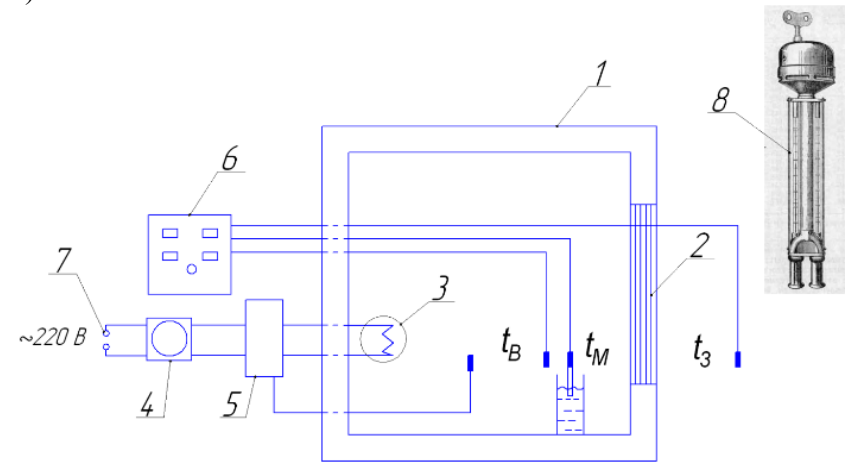

b)

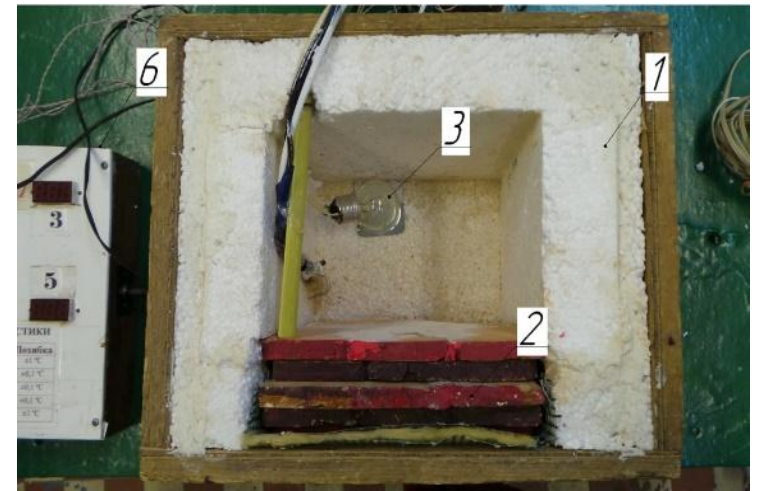

Fig. 13: Experimental installation: a) scheme; b) general view.

1 - a box with walls, insulated with foam $5 \mathrm{~cm}$ thick; 2 - a rectangular cutout for inserting thin brick plates; 3 - heating element; 4 - the sensor of the program; 5 thermostat; 6 - digital temperature sensors screen;

$$
7 \text { - power grid; } 8 \text { - psychrometer }
$$

Room temperature regime was considered at the administrative building of Poltava.

To determine the energy savings in buildings such example was performed calculations for heat insulation of external walls of foamed concrete thickness of $100 \mathrm{~mm}$.

Heat loss through exterior walls reduced to 


$$
\Delta Q=\frac{R_{\Pi}}{R_{C T}}=\frac{\frac{\delta_{2}}{\lambda_{2}}}{\frac{1}{\alpha_{B}}+\frac{\delta_{1}}{\lambda_{1}}+\frac{\delta_{2}}{\lambda_{2}}+\frac{1}{\alpha_{3}}}=
$$

$$
=\frac{\frac{0.1}{0.21}}{\frac{1}{8.7}+\frac{0.72}{0.64}+\frac{0.1}{0.21}+\frac{1}{23}}=0.27 \text {, }
$$

it means to $27 \%$.

\section{Conclusions}

The work solves the important scientific and technical problem of development and detailed scientific substantiation of the thermodynamic parameters of the production of porous heatinsulating materials. The carried out research allows us to make the following conclusions:

1) on the basis of the analysis of existing theories and methods of porous heat insulating building materials production, the absence of a holistic approach to the theoretical description of the thermal swelling of gel-like moist materials process and its connection with consumer properties is demonstrated. Consequently, the methodology for the porous materials production by the method of raw material swelling is developed, which includes the technological modes analysis, properties evaluation and methods of thermal insulation;

2) the dependence of the heat treatment technological parameters of the raw material mixture during the dilution, its composition, which allows to obtain material with minimal thermal conductivity, is experimentally determined. Besides the dependencies allowing to find the necessary mode of heat treatment to obtain the given thermophysical characteristics are found;

3) an experimental installation was developed, which allowed to determine the basic regularities of heat transfer porous material, on the basis of which data were obtained, which permissive to carry out an estimation of heat and exchange characteristics of the new dispersed porous material necessary for technological calculations;

4) on the basis of the obtained experimental dependencies, a complex mathematical model of the building thermal mode was created, as well as a program for solving equations of this model, which makes it possible to determine the basic energy characteristics;

5) the method of thermal processing of the swelling material is developed, which allows to execute the basic design and technological calculations.

\section{Acknowledgement}

The work was carried out at Poltava National Technical Yuri Kondratyuk University, and its main results were implemented within the framework of state budget applied scientific research works: "Gas hydrate technologies application in the development of traditional and gas hydrate gas fields" (state registration number 0113U00857), "Investigation of the thermodynamic parameters influence phase transitions in systems with gas hydrates on the efficiency of gas hydrate technologies" (state registration number (0115U002420), "Resource saving technologies restoration and reconstruction of residential, public and industrial buildings and structures protecting of civil defense" (state registration number 0116U002567).

\section{References}

[1] Nimmo, J.R. (2004) Porosity and Pore Size Distribution, in Hillel, D., ed. Encyclopedia of Soils in the Environment: London, Elsevier, v. 3, p. 295-303.

[2] Pavlenko A., Usenko B., Koshlak H. Analys is of thermal peculiarities of alloy in gwith special properties. Metallurgical and Mining Industry. №2. (2014), pp. 50-55.

[3] Lopez-Pamies O., Ponte Castañeda P., Idiart M. Effects of internal pore pressure on closed-cellelastomericfoams. International Journal of Solids and Structures. Vol. 49. № 19-20, (2012), pp. 2793-2798 https://doi.org/10.1016/j.ijsolstr.2012.02.024

[4] Leshchenko M. V., Semko V. O. Thermal characteristics of the external walling made of cold-formed steel studs and polystyrene concrete. Magazine of Civil Engineering. № 8, (2015), pp. 44-55. https://doi.org/10.5862/MCE.60.6

[5] Aboudi J., Arnold S., Bednarcyk B. (2012) Micromechanics of Composite Materials: A Generalized Multiscale Analysis Approach. Elsevier, 1006 p. ISBN:9780123977595

[6] Pavlenko A., Koshlak H. Design of processes of thermal bloating of silicates. Metallurgical and Mining Industry. №2, (2015), pp. 118122.

[7] Pavlenko A.M., Shumska L.P. Determination of energy parameters of technology of thermal pore formation. Metallurgical and Mining Industry. №11, (2016), pp. 99-104.

[8] Semko O., Yurin O., Avramenko Yu., Skliarenko S. Thermophysical aspects of cold roof spaces. MATEC Web of Conferences. Vol. 116, (2017), p. 02030. https://doi.org/10.1051/matecconf/201711602030

[9] Yurin O., Galinska T. Study of heat shielding qualities of brick wall angle with additional insulation located on the outside fences. MATEC Web of Conferences. Vol. 116, (2017), p. 02039. https://doi.org/10.1051/matecconf/201711602039

[10] Olena Filonenko. Definition of the parameters of thermal insulation in the zone of building foundation according to the ground freezing depth. Energy Efficiency. Vol. 11, Issue 3, (2017), pp. 603-626. https://doi.org/10.1007/s12053-017-9600-X 